Abstract

\title{
Stability of Chocolates Enriched with Cocoa Shell during Storage ${ }^{+}$
}

\author{
Veronika Barišić, Ante Lončarić, Ivana Flanjak, Antun Jozinović, Stela Jokić*, Drago Šubarić, Jurislav Babić, \\ Borislav Miličević and Đurđica Ačkar
}

Citation: Barišić, V.; Lončarić, A.; Flanjak, I.; Jozinović, A.; Jokić, S.; Šubarić, D.; Babić, J.; Miličević, B. Ačkar, Đ. Stability of Chocolates Enriched with Cocoa Shell during Storage. Proceedings 2021, 70, 3 https://doi.org/10.3390/ foods_2020-08534

Published: 23 November 2020

Publisher's Note: MDPI stays neutral with regard to jurisdictional claims in published maps and institutional affiliations.

Copyright: $\odot 2020$ by the authors. Licensee MDPI, Basel, Switzerland. This article is an open access article distributed under the terms and conditions of the Creative Commons Attribution (CC BY) license (http://creativecommons.org/licenses/by/4.0/).
Faculty of Food Technology Osijek, Josip Juraj Strossmayer University of Osijek, Franje Kuhača 18, 31000 Osijek, Croatia; veronika.barisic@ptfos.hr (V.B.); ante.loncaric@ptfos.hr (A.L.); ivana.flanjak@ptfos.hr (I.F.); antun.jozinovic@ptfos.hr (A.J.); dsubaric@ptfos.hr (D. Š.); jbabic@ptfos.hr (J.B.); borislav.milicevic@ptfos.hr (B.M.); dackar@ptfos.hr (Đ.A.)

* Correspondence: stela.jokic@ptfos.hr

+ Presented at the 1st International Electronic Conference on Food Science and Functional Foods, 10-25 November 2020; Available online: https://foods_2020.sciforum.net/.

\begin{abstract}
The stability of chocolate is mainly influenced by cocoa butter re-crystallization during storage, shown through fat bloom (appearance of white layers of cocoa butter on chocolate surface). The aim of this study was to examine the influence of cocoa shell addition on stability of dark and milk chocolate over a one-year storage period. Dark and milk chocolates were produced in a ball mill. Four chocolates were produced, two with the addition of cocoa shell (5\% in milk and $15 \%$ in dark) and two control chocolates without the addition. The effect of cocoa shell on chocolate stability was examined by determining total color change and whiteness index (calculated from parameters $L^{*}, a^{*}$ and $b^{*}$ determined using chromameter), total polyphenol content (TPC) (using the Folin-Ciocalteau method) and thermo-physical properties (using differential scanning calorimetry). Total color change and whiteness index were lower in chocolates with cocoa shell than in control samples. Over a period of one year, milk and dark chocolate with cocoa shell had lower enthalpy. Total polyphenol content in all chocolates did not change significantly through the storage period, although chocolates with cocoa shell had lower TPC because part of the cocoa liquor was replaced with cocoa shell.
\end{abstract}

Keywords: chocolate; cocoa shell; polyphenols; ball mill; chocolate stability

Supplementary Materials: The following are available online at www.mdpi.com/2504-3900/70/1/3/s1.

Funding: This work has been supported in part by Croatian Science Foundation under the project "Application of cocoa husk in production of chocolate and chocolate-like products" (UIP 2017-058709).

Institutional Review Board Statement: Not applicable.

Informed Consent Statement: Not applicable.

Data Availability Statement: The data presented in this study are available on request from the corresponding author. 